\title{
COMPARISON OF NALTREXONE AND QUATERNARY NALTREXONE AFTER SYSTEMIC AND INTRACEREBROVENTRICULAR ADMINISTRATION IN PIGEONS*
}

\author{
C. P. FrancF, ** Jill II. Amamst and I. H. Woons§ \\ Departments of Psychology and Pharmacology, The University of Michigan, Ann Arbor, MI 48109-0010, \\ U.S.A.
}

(Accepted 15 September 1986)

\begin{abstract}
Summary - The behavioral effects of naltrexone and quaternary naltrexone were evaluated in two groups of pigeons. One group responded under a fixed-ratio schedule of food reinforcement and was trained to discriminate between $3.2 \mathrm{mg} / \mathrm{kg}$ morphine (i.m.) and saline. Drug-appropriate responding occurred in a dose-related manner to morphine, given intramuscularly and intraventricularly. When administered intraventricularly morphine was 50 times more potent as a discriminative stimulus and $50-100$ times more potent at suppressing responding. Naltrexone, given intraventricularly and intramuscularly, attenuated the discriminative stimulus effects of morphine. Quaternary naltrexone was more potent at suppressing responding when administered intraventricularly but it failed to attenuate the discriminative stimulus effects of morphine. A second group of pigeons, responding under a variable-interval schedule of food reinforcement, was treated with $100.0 \mathrm{mg} / \mathrm{kg} /$ day of morphine. Naltrexone and quaternary naltrexone suppressed responding by both routes of administration. Naltrexone was approximately equipotent when given intramuscularly or intraventricularly, and the doses that suppressed responding were 50-500 times smaller than doses required to suppress responding in untreated pigeons. Although quaternary naltrexone was 1800 times more potent when given intraventricularly, the doses necessary to suppress responding by each route were the same as doses required in untreated pigeons. These results extend the conditions under which a quaternary derivative of naltrexone failed to display antagonist activity in the pigeon. The utility of this compound for characterizing central and peripheral mechanisms of action has not been established in different species and testing conditions and, therefore, appears to be appropriate only under conditions in which it is evaluated after systemic, as well as central, administration.
\end{abstract}

Key words: naltrexone, naltrexone methobromide, morphine, opioid antagonism, pigeon, intracerebroventricular.

Because of their presumed inability to penetrate the blood-brain barrier (BBB), quaternary derivatives of opioid antagonists have been used extensively for studies of central and peripheral mechanisms of drug action (e.g. Brown and Goldberg, 1985). Typically, both the tertiary and quaternary forms of a compound are administered systemically; if the tertiary form exerts a pharmacological effect that is not mimicked by the quaternary form, it is often concluded that this effect was produced in the central nervous system (CNS). Quaternary naltrexone, the $N$-methyl derivative of the opioid antagonist nal-

*Portions of these data were presented at the 92nd Annual Convention of the American Psychological Association, Toronto, August, 1984 (France, 1984).

**Present address: Laboratory of Psychobiology, Harvard Medical School, 25 Shattuck Street, Boston, MA 02115, U.S.A.

†Present address: Department of Pharmacology, Emory University School of Medicine, Atlanta, GA 30322, U.S.A.

\$Requests for reprints should be addressed to Dr J. H. Woods, Department of Pharmacology, 6322 Medical Science I Building, University of Michigan Medical School, Ann Arbor, MI 48109-0010, U.S.A. trexone, is thought to have antagonistic properties similar to those of its parent compound, differing only in its ability to cross the blood-brain barrier and its lower affinity for opioid binding sites (e.g. Valentino, Katz, Medzihradsky and Woods, 1983). Consequently, under conditions in which systemically-administered naltrexone, but not quaternary naltrexone, attenuates the actions of opioid agonists, it is assumed that these agonist effects are mediated by the CNS.

Many studies have shown that systemicallyadministered quaternary naltrexone is not an effective opioid antagonist under a variety of experimental conditions, however, very few experiments have demonstrated conclusively that the lack of antagonistic action observed with quaternary naltrexone is due, exclusively, to its inability to penetrate the blood-brain barrier. In order to directly confirm the hypothesis that quaternary naltrexone is an effective antagonist in vivo, but fails to antagonize the actions of morphine under some experimental conditions because of limited distribution to the CNS, it is important to demonstrate antagonism when quatcrnary naltrexone is administered dircetly into the 
CNS. Although there are reports that systemicallyadministered quaternary derivatives of opioid antagonists attenuate peripherally-mediated effects of morphine (e.g. Russell, Bass, Goldberg, Schuster and Merz, 1982) and attenuate some centrally-mediated effects of morphine when administered directly into the CNS (e.g. Gmerek, Cowan and Woods, 1986), there are many situations in which these antagonists are used routinely despite no clear demonstration of antagonist activity by any route of administration.

It was previously reported (France, Adams and Woods, 1985) that quaternary naltrexone, administered systemically or centrally, failed to attenuate the rate-suppressing effects of morphine in pigeons, whereas very small doses of naltrexone, administered intramuscularly (i.m.) or intracerebroventricularly (i.c.v.), antagonized the effects of morphine. Those results suggested that the antagonistic actions of quaternary naltrexone might have been limited by its direct rate-suppressing effects. In light of its reduced binding affinity compared to naltrexone (e.g. Valentino, Herling, Woods, Medzihradsky and Mcrz, 1981), the doses of quaternary naltrexone administered centrally that should have antagonized the effects of morphine, were doses that suppressed responding markedly when administered alone. Thus, it was possible that quaternary naltrexone might antagonize the effects of morphine on schedule-controlled behavior in pigeons, but, perhaps, only under conditions in which the direct effects of the drug could be avoided. One possible way of avoiding direct effects associated with large doses of antagonists is to evaluate compounds in situations where animals are more sensitive to antagonistic actions.

In the present experiments, the antagonistic actions of naltrexone and quaternary naltrexone were compared in pigeons trained to discriminate a small dose of morphine from saline and under other experimental conditions in which very small doses of opioid antagonists have been shown to produce behavioral effects. Specifically, naltrexone and quaternary naltrexone given intramuscularly and intraventricularly were compared for their ability to attenuate the discriminative stimulus effects of $3.2 \mathrm{mg} / \mathrm{kg}$ of morphine (i.v.) and to suppress food-maintained responding in pigeons receiving $100.0 \mathrm{mg} / \mathrm{kg} /$ day of morphine. Although the rate-suppressing effects of opioid antagonists in untreated animals are thought not to be related to opioid mechanisms, the ability of very small doses of antagonists to suppress responding in morphine-treated subjects is believed to be due to opioid actions (France and Woods, 1985a; Valentino et al., 1981; 1983; Young and Thompson, 1978 ) and is often related to withdrawal of opioids.

\section{EXPERIMENT I: DRUG DISCRIMINATION}

\section{Method}

Subjects. Experimentally naive white Carneaux pigeons (Palmetto, Sumter, South Carolina) were deprived to $80 \%$ of their free feeding weight. The reduced body weight was maintained by food earned during experimental sessions as well as supplementary feeding (mixed grain and Purina Pigeon Checkers) in the home cage where grit and water were available continuously.

Apparatus. Experiments were conducted in ventilated, sound-attenuated operant chambers measuring $33 \times 28 \times 36 \mathrm{~cm}$ high. Three translucent response keys $(2.4 \mathrm{~cm}$ in diameter) were located on one wall $25 \mathrm{~cm}$ above the chamber floor. In Experiment I, only the center and left keys were used and they could be illuminated by 7-W lights located behind each key. Food was presented through a $5 \times 5 \mathrm{~cm}$ opening directly below the center response key. Programming, recording and collection of data were accomplished with a Texas Instruments, Inc. (Dallas, Texas) 960A computer and cumulative response recorders (Ralph Gerbrands, Arlington, Massachusetts).

Procedure. Pigeons were trained to discriminate between intramuscular injections of morphine and saline under a fixed-ratio 20 (FR 20) schedule of presentation of food. Each daily session was preceded by an intramuscular injection $(1 \mathrm{ml} / \mathrm{kg}$ saline or $3.2 \mathrm{mg} / \mathrm{kg}$ morphine), after which the subject was placed in the experimental chamber for a pretreatment period of $15 \mathrm{~min}$. During the pretreatment period, the chamber was dark and key pecks had no programmed consequences. Upon expiration of the pretreatment period, the center and left keys were illuminated red and the pigeons could earn a 4 -sec access to mixed grain by emitting 20 consecutive responses on the injection-appropriate key (left key morphine-appropriate, center key saline-appropriate, for all subjects). Responses on the injectioninappropriate key reset the fixed ratio requirement on the appropriate key. Training sessions ended after 30 presentations of food or $20 \mathrm{~min}$, whichever occurred first. Two criteria had to be satisfied prior to the beginning of testing: (1) fewer than 20 responses could be emitted on the injection-inappropriate key prior to the first presentation of food; and (2) at least $90 \%$ of the total session responses had to be emitted on the injection-appropriate key. When these criteria had been satisfied for 5 consecutive days (i.e. drug, saline, drug, drug, saline) intraventricular cannulae were implanted and testing began.

Surgery. The surgical procedure was identical to that previously described (France et al., 1985). Briefly, pigeons were anaesthetized with $2.5 \mathrm{ml} / \mathrm{kg}$ of Chloropent (chloral hydrate and pentobarbital [Fort Dodge Laboratories, Inc., Fort Dodge, Iowa]) and $5.0 \mathrm{mg} / \mathrm{kg}$ of ketamine and a chronic, indwelling, $22 \mathrm{~g}$ cannula (Plastic Products, Inc., Roanoke, Virginia) was implanted using stereotaxic procedures and a Revzin adaptor (Karten and Hodos, 1967). A $28 \mathrm{~g}$ dummy cannula (Plastic Products, Inc.) was inserted into the guide cannula except during infusions. The patency of the cannula was assessed monthly by radiographs taken immediately after an intraventricular injection $(10-20 \mu 1)$ of radioopaque dye 
(Conray [Mallinckrodt, Inc., St. Louis, Missouri]). Only data obtained from experiments that were both preceded and followed by radiographs clearly showing diffusion of the dye throughout the ventricles were used in the analysis.

Testing. After the testing criteria had been satisfied for 5 consecutive days and positive placement of the cannula had been verified radiographically, tests were conducted whenever subjects met criteria for consecutive training days with drug and saline. Test sessions were identical to training sessions with the exception that 20 consecutive responses on either key produced food. Initially, dose-effect curves were determined for morphine administered intramuscularly or intraventricularly alone. For tests of antagonism, a single injection of naltrexone or quaternary naltrexone was administered intramuscularly or intraventricularly $10 \mathrm{~min}$ prior to an intramuscular injection of morphine $(3.2 \mathrm{mg} / \mathrm{kg})$. Morphine was administered immediately prior to the beginning of the test session. For comparison, selected doses of naltrexone and quaternary naltrexone were administered intramuscularly or intraventricularly $10 \mathrm{~min}$ prior to an intramuscular injection of saline.

Discrimination data are expressed as the mean percentage of responses emitted on the morphineappropriate key \pm 1 SEM for 6 pigeons. Data for response rates are expressed as the mean number of responses per second \pm 1 SEM. Fixed doses (e.g. $100.0 \mu \mathrm{g}$ ) were administered intraventricularly, however, for the purposes of comparison these doses were converted to $\mathrm{mg} / \mathrm{kg}$ body weight. Due to limited life of the cannulae, 13 subjects were needed to complete all the dose-effect curves. Data from the same 6 subjects were used to complete a dose-effect curve for each compound.

Drugs. The drugs used in this experiment were morphine sulfate (Mallinckrodt, Inc., St. Louis, Missouri), naltrexone hydrochloride (Endo Laboratories, Inc., Garden City, New York), and naltrexone methobromide (MRZ 2663BR) [quaternary naltrexone]; Dr H. Merz, C. H. Boehringer, Sohn, Ingelheim am Rhein, Federal Republic of Germany). Morphine and naltrexone were dissolved in sterile $0.9 \%$ saline for systemic administration and in sterile water for central administration. Naltrexone methobromide was dissolved in sterile water only.

Systemic injections were made to the breast muscle in a volume of $1 \mathrm{ml} / \mathrm{kg}$ body weight. Central injections of $10 \mu 1$ were performed manually over a period of 1-2 min with a $100 \mu \mathrm{l}$ Hamilton syringe, connected to a $28 \mathrm{~g}$ injection cannula (Plastic Products, Inc.) by PE 20 polyethylene tubing. The injection cannula protruded $0.5 \mathrm{~mm}$ beyond the tip of the guide cannula and was held in place for 2 min after the infusion in order to reduce possible backflow of fluid.

\section{Results}

Thirteen pigeons acquired the morphine-saline discrimination after an average of 59 training sessions (range 37-75). The average duration of patency of the cannulae in the 5 pigeons eventually judged to have negative placement of the cannula was $5.5 \pm 1.3$ months. One pigeon died from causes unrelated to cannulation and one pigeon dislodged its cannula in the home cage. Six cannulae were patent at the termination of the experiment after an average of $10.8 \pm 1.9$ months.

Morphine, administered intramuscularly or intraventricularly, produced responding on the drugappropriate key in a dose-related manner and at larger doses suppressed food-maintained responding (Fig. 1). The doses of morphine required for complete generalization (i.e. greater than $90 \%$ drugappropriate responding) were $32.0-100.0 \mu \mathrm{g}(0.07-$ $0.23 \mathrm{mg} / \mathrm{kg}$ ) intraventricularly and $3.2-10.0 \mathrm{mg} / \mathrm{kg}$ intramuscularly. Morphine was approximately 50 times more potent as a discriminative stimulus when administered intraventricularly. Intraventricular administration of $32.0-100.0 \mu \mathrm{g}$ of morphine suppressed responding to less than one response per sec, while a lose of $32.0 \mathrm{mg} / \mathrm{kg}$ was required to suppress responding to less than one response per sec, when morphine was administered intramuscularly. Although doses of morphine larger than $100.0 \mu \mathrm{g}$ were not tested intraventricularly, the difference in potency
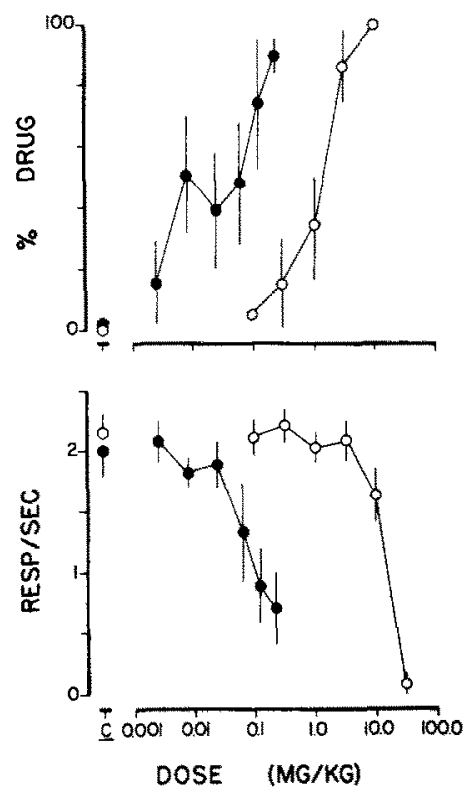

Fig. 1. Dose-effect curves for morphine administered intraventricularly (closed symbols) and intramuscularly (open symbols) in pigeons trained to discriminate between intramuscular injections of $3.2 \mathrm{mg} / \mathrm{kg}$ morphine and saline. Ordinates: upper panel, mean percentage of responses emitted on the morphine-appropriate key \pm 1 SEM; lower panel, average response rate \pm 1 SEM expressed as responses per sec. Abscissae: dose in $\mathrm{mg} / \mathrm{kg}$ body weight. Data points above $C$ represent control sessions that were preceded by a single intraventricular injection of $10 \mu 1$ sterile water (closed symbols) or an intramuscular injection of $1 \mathrm{ml} / \mathrm{kg}$ saline (closed symbols). Two pigeons failed to respond after intraventricular injections of morphine larger than $32.0 \mu \mathrm{g}$ $(0.07 \mathrm{mg} / \mathrm{kg})$. 
for suppressing responding by the two routes of administration appeared to be approximately 100-fold (lower panel, Fig. 1).

Neither naltrexone nor quaternary naltrexone substituted completely for morphine as discriminative stimuli (data not shown). Naltrexone produced a maximum of $24.0 \pm 12.6 \%$ morphine-appropriate responding at a dose of $100.0 \mu \mathrm{g}(0.23 \mathrm{mg} / \mathrm{kg}$ i.c.v. $)$. Quaternary naltrexone produced a maximum of $39.7 \pm 15.1 \%$ morphine-appropriate responding at a dosc of $56.0 \mu \mathrm{g}(0.12 \mathrm{mg} / \mathrm{kg}$ i.c.v. $)$. Quaternary naltrexone produced convulsions in two pigeons tested with $100.0 \mu \mathrm{g}$ (i.c.v.).

Injection of $100.0 \mu \mathrm{g}(0.23 \mathrm{mg} / \mathrm{kg})$ naltrexone intraventricularly $10 \mathrm{~min}$ prior to $3.2 \mathrm{mg} / \mathrm{kg}$ morphine resulted in an average of $20.5 \pm 14.9 \%$ morphineappropriate responding (Fig. 2). Thus, the discriminative stimulus effects of the training dose of morphine $(3.2 \mathrm{mg} / \mathrm{kg})$ were antagonized in a dose-related manner by naltrexone given by either route, and the potency of naltrexone as an antagonist was similar by the two routes of administration. The dose of naltrexone given intramuscularly required for a similar degree of antagonism was $0.1 \mathrm{mg} / \mathrm{kg}$ (compare open and closed diamonds, Fig. 2). When adminis-
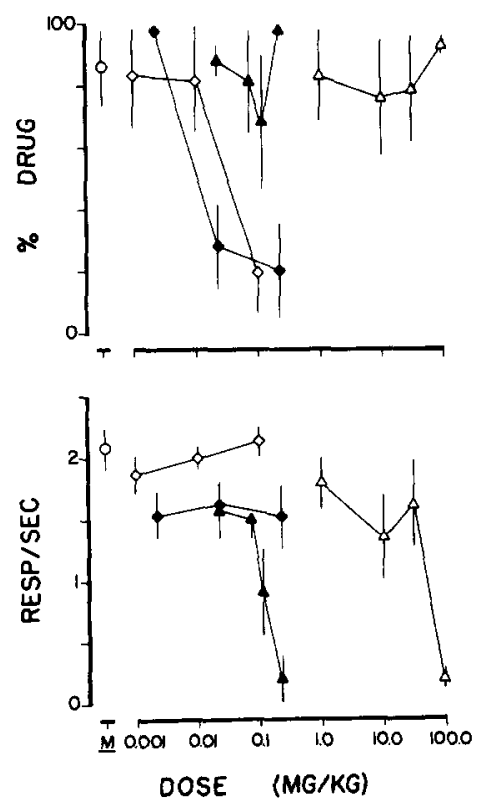

Fig. 2. Dose-effect curves for naltrexone (diamonds) and quaternary naltrexone (triangles) administered 10 minutes prior to an injection of $3.2 \mathrm{mg} / \mathrm{kg}$ morphine (i.m.). Naltrexone and quaternary naltrexone were administered intraventricularly (open symbols) or intramuscularly (closed symbols). Data points above $M$ represent sessions in which only $3.2 \mathrm{mg} / \mathrm{kg}$ morphine was administered. Two pigeons did not respond after intraventricular injections of quaternary naltrexone larger than $32.0 \mu \mathrm{g}(0.07 \mathrm{mg} / \mathrm{kg})$, and only one pigeon responded at a dose of $100.0 \mu \mathrm{g}$ $(0.22 \mathrm{mg} / \mathrm{kg})$ quaternary naltrexone (i.c.v.). One pigeon did not respond after an injection of $32.0 \mathrm{mg} / \mathrm{kg}$ quaternary naltrexone (i.m.), and three pigeons did not respond at a dose of $100.0 \mathrm{mg} / \mathrm{kg}$ quaternary naltrexone (i.m.). Other information as in Fig. 1. tered in combination with $3.2 \mathrm{mg} / \mathrm{kg}$ morphine, effective antagonistic doses of tertiary naltrexone did not suppress food-maintained responding (lower panel, Fig. 2).

Up to doses that suppressed responding, quaternary naltrexone failed to attenuate the discriminative stimulus effects of $3.2 \mathrm{mg} / \mathrm{kg}$ morphine (open and closed triangles, Fig. 2). A dose of $3.2 \mathrm{mg} / \mathrm{kg}$ morphine in combination with quaternary naltrexone, up to doses of $100.0 \mathrm{mg} / \mathrm{kg}$ (i.m.) and $100.0 \mu \mathrm{g}(0.23 \mathrm{mg} / \mathrm{kg})$ (i.c.v.), produced at least $68 \%$ morphine-appropriate responding. Although there was a suggestion that $56.0 \mu \mathrm{g}$ quaternary naltrexone given intraventricularly partially attenuated the discriminative stimulus effects of $3.2 \mathrm{mg} / \mathrm{kg}$ morphine, three of the four pigeons not suppressed with that combination of doses responded $90.0 \pm 1.8 \%$ on the morphine key. Furthermore, the one pigeon that responded at the next largest dose of quaternary naltrexone $(100.0 \mu \mathrm{g})$ in combination with morphine, responded $98.4 \%$ on the morphine key. When administered $10 \mathrm{~min}$ prior to $3.2 \mathrm{mg} / \mathrm{kg}$ morphine, quaternary naltrexone was $300-1000$ times more potent at suppressing responding by the intraventricular route.

\section{EXPERIMENT II: MORPHINE-TREATED PIGEONS}

\section{Method}

Subjects. Three White Carneaux pigeons, that had been used in a previous experiment (France et al., 1985), were maintained at $80 \%$ of their free-feeding weight and housed individually with water and grit available continuously. The reduced body weight was maintained by food earned during experimental sessions and supplementary feeding in the home cage (Purine Pigeons Checkers and mixed grain). These pigeons had been implanted with chronic, indwelling, intraventricular cannulae and had received intramuscular and intraventricular injections of morphine, naltrexone, and quaternary naltrexone.

Apparatus. Experimental chambers, as well as materials for controlling and recording experimental events, were identical to those described in Experiment I. For Experiment II, only the center response key was used and was illuminated green during periods of availability of food.

Procedure. Responding was maintained under a variable-interval $30 \mathrm{sec}$ (VI $30^{\prime \prime}$ ) schedule of presentation of food. Under this schedule, the first response after an average interval length of $30 \mathrm{sec}$ produced a 4-sec access to mixed grain. Responses prior to the end of the interval were recorded but had no programmed consequence.

Daily sessions consisted of five, discrete 15 -min trials. Each trial began with a 10 min pretreatment period, during which the chamber was dark and key pecks had no programmed consequences and a 5 -min response period, during which food could be earned under the variable interval $30^{\prime \prime}$ schedule. Experimental scssions werc conducted 5 days per week at 
$1500 \mathrm{hr}, 6 \mathrm{hr}$ after administration of the maintenance dose of morphine $(0900 \mathrm{hr})$.

Initially, pigeons were treated with $10.0 \mathrm{mg} / \mathrm{kg} /$ day of morphine for 28 days and sensitivity to the ratesuppressing effects of cumulative doses of naltrexone given intramuscularly was assessed weekly. Beginning on day 29 , the maintenance dose of morphine was increased to $100.0 \mathrm{mg} / \mathrm{kg} /$ day. These conditions remained constant for the duration of the experiment (additional 150 days).

Testing. Tests were conducted on Tuesday and Friday of each week and both single- and cumulativedose procedures were used. For the first 6 weeks of the experiment, cumulative dose-effect curves for naltrexone were determined weekly to monitor any changes in sensitivity to the antagonist during treatment with morphine. The cumulative-dose procedure involved the administration of increasing doses of drug prior to each trial, such that the cumulative dose increased by $\frac{1}{2} \log$ unit per trial. For single dose experiments, a single injection of naltrexone or quaternary naltrexone, given intramuscularly or intraventricularly, was administered immediately prior to the first trial. Prior to some non-test sessions, pigeons received an intramuscular injection of saline $(1.0 \mathrm{mg} / \mathrm{kg})$ or an intraventricular injection of sterile water $(10 \mu 1)$. The order in which doses and drugs were tested varied non-systematically between subjects and body weight was recorded for each subject immediately before and after each test session.

Response rates are summarized as the mean rate \pm 1 SEM over a 5 -trial test session for 3 pigeons and are expressed as a percentage of the non-injection control rates during treatment with $100.0 \mathrm{mg} / \mathrm{kg} /$ day of morphine. Control rates for each animal were averaged over all 5 trials of 18 non-injection sessions and these values were used to calculate percentage response rates and SEM. Doses required to suppress responding to $50 \%$ of the control rate were determined for each subject by drawing a line between the data points immediately above and below the 50\% suppression level and interpolating the dose required for that level of suppression.

Drugs. The drugs, vehicle solutions and methods of administration were as described in Experiment $I$.

Results

Response rates were not affected by daily administration of $10.0 \mathrm{mg} / \mathrm{kg}$ of morphinc. All three pigcons responded at or near $100 \%$ of the control rate throughout the treatment period with $10.0 \mathrm{mg} / \mathrm{kg} /$ day of morphine. Daily injections of $10.0 \mathrm{mg} / \mathrm{kg}$ morphine did, however, produce an increase in sensitivity to the rate-suppressing effects of naltrexone. During the first week of treatment with $10.0 \mathrm{mg} / \mathrm{kg} /$ day morphine, the mean dose of naltrexone required to suppress responding to $50 \%$ of the control rate was $0.64 \mathrm{mg} / \mathrm{kg}$ (i.m.). By the fourth week of treatment at this dose, a comparable degree of suppression was produced by $0.33 \mathrm{mg} / \mathrm{kg}$.
Response rates were suppressed to an average of $16 \%$ of the control rate on the first day of $100.0 \mathrm{mg} / \mathrm{kg} /$ day of morphine. By the second day of treatment, however, responding had recovered to $44 \%$ of control. Thereafter, response rates increased more slowly, but failed to recover completely over the duration of treatment with $100.0 \mathrm{mg} / \mathrm{kg} / \mathrm{day}$ of morphine. The average rate for the three pigeons during treatment with $100.0 \mathrm{mg} / \mathrm{kg} /$ day of morphine was $61 \%(1.29 \pm 0.26$ responses per sec $)$ of the control rate $(2.11 \pm 0.12$ responses per sec). Consequently, the effects of naltrexone and quaternary naltrexone during treatment with $100.0 \mathrm{mg} / \mathrm{kg} /$ day of morphine were expressed as a percentage of the non-injection control rate during treatment with morphine.

In the first week of $100.0 \mathrm{mg} / \mathrm{kg} /$ day of morphine, a dose of $0.13 \mathrm{mg} / \mathrm{kg}$ naltrexone suppressed responding to $50 \%$ of the control rate. During the second week of $100.0 \mathrm{mg} / \mathrm{kg} /$ day of morphine, a comparable suppression was produced by a dose of $0.06 \mathrm{mg} / \mathrm{kg}$ naltrexone. Because this sensitivity to naltrexone was similar to the sensitivity of pigeons maintained for long periods of time on $100.0 \mathrm{mg} / \mathrm{kg} /$ day of morphine (e.g. France and Woods, 1985a), experiments with single intramuscular and intraventricular injections of naltrexone and quaternary naltrexone began the following week.

In pigeons, maintained on $100.0 \mathrm{mg} / \mathrm{kg} /$ day of morphine, naltrexone and quaternary naltrexone suppressed responding in a dose-related manner by both routes of administration (Fig. 3). The doses of

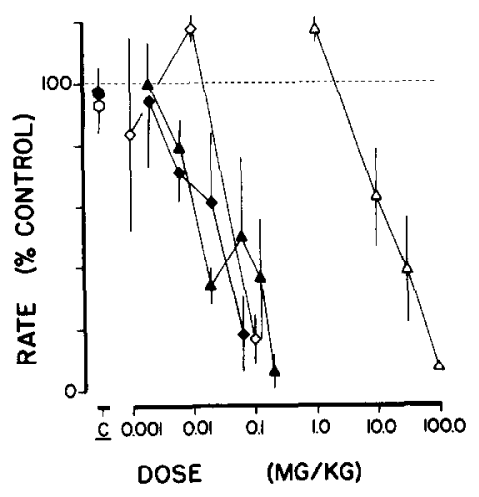

Fig. 3. Dose-effect curves for naltrexone (diamonds) and quaternary naltrexone (triangles) administered intraventricular (closed symbols) and intramuscular (open symbols) in three morphine-treated $(100.0 \mathrm{mg} / \mathrm{kg} /$ day $)$ pigeons responding under a variable interval $30^{\prime \prime}$ schedule of food presentation. Ordinate: mean response rate \pm 1 SEM expressed as a percentage of the non-injection control rate during treatment with $100.0 \mathrm{mg} / \mathrm{kg} / \mathrm{day}$ of morphine $(1.29 \pm 0.26$ responses per sec). Abscissa: dose in $\mathrm{mg} / \mathrm{kg}$ body weight. Intramuscular data are the means of two observations in each pigeon with each dose; intraventricular data represent single observations in each pigeon. Data points above $C$ represent sessions that were preceded by a single intramuscular injection of $10 \mu 1$ sterile water (closed symbols) or an intraventricular injection of $1.0 \mathrm{ml} / \mathrm{kg}$ saline (closed symbols). 
Table 1. Potencies of naltrexone and quaternary naltrexone given intraventricularly (i.c.v.) and intramuscularly (i.m.) for suppressing food-maintained responding in untreated and morphine-treated pigeons

\begin{tabular}{|c|c|c|c|c|c|c|}
\hline & \multicolumn{2}{|c|}{ Untreated $d^{\mathrm{z}, \mathrm{h}}$} & \multicolumn{2}{|c|}{ Morphine-treated $^{\mathrm{C}}$} & \multicolumn{2}{|c|}{$\begin{array}{c}\text { Relative potencies } \\
\text { between groups } \\
\text { (untreated/morphine } \\
\text { treated) }\end{array}$} \\
\hline & (i.c.v.) & (i.m.) & (i.c.v.) & (i.m.) & (i.c.v.) & (i.m.) \\
\hline $\begin{array}{l}\text { Naltrexone } \\
\text { Quaternary }\end{array}$ & $>1.22^{\mathrm{d}}$ & 26.01 & 0.03 & 0.05 & $>40.7$ & 520.2 \\
\hline Naltrexone & 0.03 & 26.20 & 0.02 & 24.55 & 1.5 & 1.1 \\
\hline
\end{tabular}

naltrexone required to suppress responding were similar for both routes of administration. Naltrexone suppressed responding to $16.6 \pm 7.8 \%$ of the control rate at a dose of $0.1 \mathrm{mg} / \mathrm{kg}$ (i.m.), and a dose of $32.0 \mu \mathrm{g} \quad(0.06 \mathrm{mg} / \mathrm{kg})$ naltrexone, given intraventricularly, suppressed responding to $17.8 \pm 12.4 \%$ of the control rate. In contrast, the doses of quaternary naltrexone required to suppress responding were different by the two routes of administration. A dose of $100.0 \mu \mathrm{g}$ quaternary naltrexone given intraventricularly suppressed response rates to less than $10 \%$ of the control rate, whereas a greater than 500 -fold increase in dose was necessary to produce a comparable suppression when quaternary naltrexone was administered intramuscularly.

Table 1 compares the potencies of naltrexone and quaternary naltrexone for suppressing foodmaintained responding in untreated (France et al., 1985) and morphine-treated pigeons under the same temporal and schedule conditions. Compared to untreated pigeons, morphine-treated pigeons were 520 times more sensitive to the rate-suppressing effects of naltrexone given intramuscularly and at least 40 times more sensitive to the effects of naltrexone given intraventricularly. In contrast, the potencies of quaternary naltrexone for either route of administration were very similar between untreated and morphinetreated pigeons.

In pigeons, treated daily with $100.0 \mathrm{mg} / \mathrm{kg}$ of morphine, changes in body weight during control sessions preceded by $10 \mu 1$ of water (i.c.v.) or $1 \mathrm{ml} / \mathrm{kg}$ saline (i.m.) were $-2.3 \pm 0.8 \mathrm{~g}(-0.48 \%)$ and $-0.2 \pm 0.7 \mathrm{~g}$ $(-0.04 \%)$, respectively. However, rate-suppression produced by naltrexone and quaternary naltrexone was accompanied by a greater loss in body weight over the $1 \frac{1}{4} \mathrm{hr}$ test session. The maximum body weight changes were: $-5.7 \pm 2.6 \mathrm{~g}(1.2 \%), 32.0 \mu \mathrm{g}$ quaternary naltrexone (i.c.v.); $-8.7 \pm 2.7 \mathrm{~g} \quad(1.8 \%)$, $100.0 \mathrm{mg} / \mathrm{kg}$ quaternary naltrexone (i.m.); $-6.7 \pm 1.7 \mathrm{~g}(1.4 \%), 32.0 \mu \mathrm{g}$ naltrexone (i.c.v.); and $-7.0 \pm 0.6 \mathrm{~g}(1.5 \%), 1.0 \mathrm{mg} / \mathrm{kg}$ naltrexone (i.m.).

The day after termination of treatment with morphine (i.e. $30 \mathrm{hr}$ morphine abstinence), responding in two of the pigeons was markedly suppressed $(46.4 \%$ and $76.9 \%$ of control), however, responding in the third pigeon accelerated to $200 \%$ of the non-injection control rate. By the second day $(54 \mathrm{hr})$ after mor- phine, only one of the three subjects responded at less than $80 \%$ of its control rate. Sensitivity to the rate-suppressing effects of a single intraventricular injection of naltrexone also returned to normal several days after the termination of treatment with morphine (data not shown). During treatment with $100.0 \mathrm{mg} / \mathrm{kg} /$ day of morphine, an injection of $32.0 \mu \mathrm{g}$ naltrexone intraventricularly suppressed responding to $17.8 \%$ of the control response rate. Four days (i.e. $102 \mathrm{hr}$ ) after the termination of treatment with morphine that dose of naltrexone failed to affect responding $(92.5 \%$ of control):

\section{DISCUSSION}

Pigeons trained to discriminate $3.2 \mathrm{mg} / \mathrm{kg}$ of morphine, given intramuscularly, from saline generalized to morphine given intraventricularly, in a doserelated manner. Furthermore, only $1 / 50$ of the effective systemic dose of morphine was required to produce morphine-appropriate responding by the intraventricular route. This finding is consistent with previous reports (e.g. Locke and Holtzman, 1985) on differences in the potency of opioid agonists as discriminative stimuli when administered centrally and peripherally and supports previous suggestions (e.g. Shannon and Holtzman, 1977) that this action of morphine might be mediated in the CNS. Furthermore, the similar potency of naltrexone, as an antagonist, by different routes of administration in pigeons was consistent with its known lipophilicity and rapid distribution throughout the periphery and CNS (Gmerek et al., 1986; Shannon and Holtzman, 1977).

A second line of evidence, used to argue that many behavioral effects of opioids are mediated in the CNS, is differential effectiveness of systemically. administered tertiary and quaternary derivatives of narcotic antagonists. For example, in rats (Brown, Robertson and Goldberg, 1983; Koob, Petit, Ettenberg and Bloom, 1984; Russell et al., 1982), pigeons (France et al., 1985; Valentino et al., 1981) and monkeys (Hein, Young, Herling and Woods, 1981; Valentino et al., 1981), systemicallyadministered quaternary naltrexone fails to antagonize the actions of morphine that are antagonized by systemically-administered naltrexone. Because naltrexone attenuates the effects of morphine in situ- 
ations in which quaternary naltrexone is ineffective, it is thought that these effects of morphine are mediated centrally. The critical assumptions upon which these conclusions are founded, regarding the sites of action of opioids, are that quaternary naltrexone is an effective antagonist but does not penetrate the blood-brain barrier. As discussed elsewhere (Brown and Goldberg, 1985), the assumptions are not well supported under a variety of testing conditions in vivo, despite demonstrations of antagonistic actions by quaternary derivatives in vitro (e.g. Valentino et al., 1981). While there are examples of opioid antagonistic actions after central administration of quaternary antagonists (Brown et al., 1983; Gmerek et al., 1986; Locke and Holtzman, 1985), many experiments that have used quaternary derivatives have not administered these compounds centrally. Thus, although there is considerable evidence indicating that the discriminative stimulus effects of morphine (Locke and Holtzman, 1985; Shannon and Holtzman, 1977) and naltrexone (Holtzman, 1985; Valentino et al., 1981) are mediated in the CNS, the results of the present study fail to support the generality of these results. Although morphine was 50 times more potent as a discriminative stimulus when administered intraventricularly, data obtained with quaternary naltrexone given intraventricularly, failed to provide additional supportive evidence of the central site of action of morphine as a discriminative stimulus. In doses up to those that suppressed responding, quaternary naltrexone, given intraventricularly, failed to attenuate the discriminative stimulus effects of morphine.

The conditions necessary for the development of supersensitivity to the behavioral actions of opioid antagonists vary between species and experimental procedures. There are, however, two pharmacological interventions by which supersensitivity has been shown to develop: repeated injections of large doses of antagonists and treatment with moderate to large doses of morphine, either acutely or chronically. Under both of these conditions, the doses of naloxone or naltrexone that disrupt schedule-controlled behavior are $1 / 10-1 / 1000$ of the doses required in untreated animals. However, neither in squirrel monkeys made supersensitive by repeated injections of large doses of naltrexone (Warren and Morse, 1985), nor in pigeons made supersensitive by chronic treatment with $100.0 \mathrm{mg} / \mathrm{kg} / \mathrm{day}$ of morphine (Valentino et al., 1981; 1983), was there an increase in the potency of systemically-administered quaternary naltrexone. Furthermore, systemically-administered quaternary antagonists do not precipitate withdrawal in morphine-dependent monkeys (Valentino et al., 1983) or dogs (Russell et al., 1982). Because there is consistently no increase in sensitivity to quaternary naltrexone in situations where there is an increase in sensitivity to naltrexone, it has been assumed that these effects of naltrexone are central in origin. Quaternary naltrexone does not mimic the actions of naltrexone, presumably, because it does not penetrate the blood-brain barrier.

It appears as though supersensitivity to naltrexone, after repeated exposure to large dose of naltrexone, does not develop in pigeons (Goldberg, Morse and Goldberg, 1981); however, pigeons treated acutely (France and Woods, 1985b) or chronically (France and Woods 1985a; Young and Thompson, 1978) with morphine are extremely sensitive to the behavioral effects of naltrexone. In agreement with previous rcports (Valcntino et al., 1981; 1983), systemicallyadministered naltrexone was more potent than quaternary naltrexone in suppressing food-maintained responding in morphine-treated pigeons. Furthermore, centrally administered naltrexone and quaternary naltrexone were approximately equipotent at suppressing responding in morphine-treated pigeons. Those data alone might indicate that these two compounds suppressed responding by the same or similar mechanisms when administered intraventricularly in morphine-treated pigeons and that this suppression was related to withdrawal of opioids. However, dose-effect curves, determined prior to treatment with morphine (France et al., 1985), indicated that the potency of quaternary naltrexone given intraventricularly was not markedly affected by daily injections of morphine. It is unlikely, therefore, that suppression of responding by quaternary naltrexone was related to the precipitation of withdrawal because the same potency and behavioral effects were observed in untreated pigeons. These results clearly indicate a lack of antagonistic activity to opioids by quaternary naltrexone, particularly because increased sensitivity to the actions of antagonists in morphinetreated animals has been shown to be an extremely sensitive indicator of antagonistic action (France and Woods, 1985a; Gellert and Holtzman, 1979; Valentino et al., 1983).

Many quaternary opioids have lower affinity than their tertiary forms for opioid binding sites (e.g. Kosterlitz and Waterfield, 1975); quaternary naltrexone, for example, has approximately a 50-fold lower affinity than naltrexone (Valentino et al., 1981; 1983). Quaternary antagonists also are not highly specific and have been shown to bind to a variety of receptor types (e.g. Argentieri and McArdle, 1983). It is possible, therefore, that some non-opioid action of quaternary naltrexone accounts for its ratesuppressing effects, both in untreated and in morphine-treated pigeons, and that this effect precludes an antagonist activity for quaternary naltrexone using schedule-controlled behavior in pigeons. Quaternary naltrexone might, however, share other effects with naltrexone that are related to opioid withdrawal, as indicated by the similar weight loss observed after administration of naltrexone or quaternary naltrexone in morphine-treated pigeons. Finally, because quaternary derivatives, in general, do not pass readily through biological membranes, quaternary naltrexone may not distributc widely 
within the CNS when administered intraventricularly in pigeons. Thus, the antagonistic actions of quaternary naltrexone given intraventricularly might be restricted to periventricular sites. $N, N$-Diallyl nalorphine, a hydrophilic derivative of nalorphine, attenuates the effects of heroin in rats, as measured by an increase in the rate of self-administration of heroin, but only when injected to specific regions of the brain (Britt and Wise, 1983). Injections of quaternary naltrexone to discrete areas of the brain might also result in antagonistic actions to opioids in pigeons.

The results of these experiments suggest that the use of quaternary derivatives for determining central and peripheral mechanisms of action requires these compounds be administered over a wide range of doses, centrally as well as peripherally. Undoubtedly, the appropriate use of quaternary naltrexone in other species (e.g. Locke and Holtzman, 1985) has provided valuable information on the sites of action of opioids and, furthermore, the results reported here may be restricted to a single species or, perhaps, to some measures of the action of drugs that utilize schedulecontrolled behavior. Nevertheless, the assumption that antagonist activity cannot be observed with systemically-administered quaternary derivatives only because these compounds do not cross the blood-brain barrier is not widely supported. Failure to characterize the spectrum of action of quaternary derivatives under particular testing conditions could lead to erroneous conclusions regarding central and peripheral mechanisms of action of opioids.

Acknowledgements - This work was supported by U.S. Public Health Service Grant DA 00154.

\section{REFERENCES}

Argentieri T. M. and McArdle J. J. (1983) Interaction of the opiate antagonist, naltrexone methyl bromide, with the acetylcholine receptor system of the motor end-late. Brain Res. 277: 377-379.

Britt M. D. and Wise R. A. (1983) Ventral tegmental site of opiate reward: antagonism by a hydrophilic opiate receptor blocker. Brain Res. 258: 105-108.

Brown D. R. and Goldberg L. I. (1985) The use of quaternary narcotic antagonists in opiate research. $\mathrm{Neu}$ ropharmacology 24: 181-191.

Brown D. R., Robertson M. J. and Goldberg L. I. (1983) Reversal of morphine-induced catalepsy in the rat by narcotic antagonists and their quaternary derivatives. Neuropharmacology 22: 317-321.

France C. P. (1984) Intracerebroventricular morphine, naltrexone and quaternary naltrexone in the pigeon. Pharmac. Biochem. Behav. 20: 991.

France C. P. and Woods J. H. (1985a) Effects of morphine, naltrexone and dextrorphan in untreated and morphinetreated pigeons. Psychopharmacology 85: 377-382.

France C. P. and Woods J. H. (1985b) Opiate agonistantagonist interactions: application of a three-key drug discrimination procedure. J. Pharmac. exp. Ther. 234: $81-89$.

France C. P., Adams J. U. and Woods J. H. (1985) Intracerebroventricular drug administration in pigeons. Pharmac. Biochem. Behav. 23: 731-736.

Gellert V. F. and Holtzman S. G. (1979) Discriminative stimulus effects of naltrexone in the morphine-dependent rat. J. Pharmac. exp. Ther. 211: 596-605.

Gmerek D. E., Cowan A. and Woods J. H. (1986) Independent central and peripheral mediation of morphineinduced inhibition of gastrointestinal transit in rats. $J$. Pharmac. exp. Ther. 236: 8-13.

Goldberg S. R., Morse W. H. and Goldberg D. M. (1981) Acute and chronic effects of naltrexone and naloxone on schedule-controlled behavior of squirrel monkeys and pigeons. J, Pharmac, exp. Ther. 216: 500-509.

Hein D. W., Young A. M., Herling S. and Woods J. H. (1981) Pharmacological analysis of the discriminative stimulus characteristics of ethylketazocine in the rhesus monkey. J. Pharmac. exp. Ther. 218: 7-15.

Holtzman S. G. (1985) Discriminative stimulus effects of morphine withdrawal in the dependent rat: suppression by opiate and nonopiate drugs. $J$. Pharmac. exp. Ther. 233: $80-86$.

Karten J. H, and Hodos W. (1967) A Stereotaxic Atlas of the Brain of the Pigeon (Columbia livia). Johns Hopkins Univ. Press, Baltimore.

Koob G. F., Petit H. O., Ettenberg A. and Bloom F. E. (1984) Effects of opiate antagonists and their quaternary derivatives on heroin self-administration in the rat. $J$. Pharmac. exp. Ther. 229: 482-486.

Kosterlitz H. W. and Waterfield A. A. (1975) In vitro models in the study of structure-activity relationships of narcotic analgesics. Ann. Rev. Pharmac. Toxic. 15: 29-47.

Locke K. W. and Holtzman S. G. (1985) Characterization of the discriminative stimulus effects of centrally administered morphine in the rat. Psychopharmacology 87: 1-6.

Russell J., Bass P., Goldberg L. I., Schuster C. R. and Merz H. (1982) Antagonism of gut, but not central effects of morphine with quaternary narcotic antagonists. Eur. $J$. Pharmac. 78: 255-261.

Shannon H. E. and Holtzman S. G. (1977) Discriminative effects of morphine administered intracerebrally in the rat. Life Sci. 21: $585-594$.

Valentino R. J., Herling S., Woods J. H., Medzihradsky F. and Merz H. (1981) Quaternary naltrexone: evidence for the central mediation of discriminative stimulus effects of narcotic agonists and antagonists. $J$. Pharmac. exp. Ther. 217: $652-659$.

Valentino R. J., Katz J. L., Medzihradsky F. and Woods J. H. (1983) Receptor binding, antagonist, and withdrawal precipitating properties of opiate antagonists. Life Sci. 32: 2887-2896.

Warren P. H. and Morse W. H. (1985) Effects of quaternary naltrexone and chlordiazepoxide in squirrel monkeys with enhanced sensitivity to the behavioral effects of naltrexone. J. Pharmac. exp. Ther. 255: 412-417.

Young A. M. and Thompson T. (1978) Effects of naloxone on schedule-controlled behavior in morphine-maintained pigeons. J. Pharmac. exp. Ther. 205: 236-245. 